Faculdade de Ciências Econômicas UFRGS

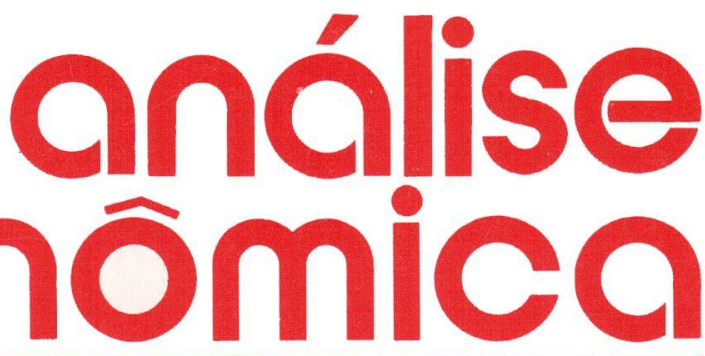

- COMÉRCIO INTERNACIONAL: UMA AGENDA DE PESQUISAS Carlos Alberto Primo Braga

- INFLACÃO E REFORMA MONETÁRIA: KEYNES E MISES Francisco Anuatti

- A ECONOMIA COMO CIÉNCIA Eleutério F.S. Prado

- REAVAlIAÇ̃̃o das PRIVATIZAÇÕES EM PAÍSES EUROPEUS

Márcio Wohlers de Almeida

- INTEGRAÇÃo BRASIL-ARGENTINA E A PRODUÇÃO DE GRÃOS José Eduardo Gutiérrez Perez Walter José Stülp

- SUBSTITUIÇÃO DE COLONOS POR TRABALHADORES ASSALARIADOS

Carlos José Caetano Bacha

- EQUILÍBRIO DISTRIBUTIVO EM MODELOS KALDORIANOS AMPLIADOS Joanílio Rodolpho Teixeira Jorge Thompson Araújo

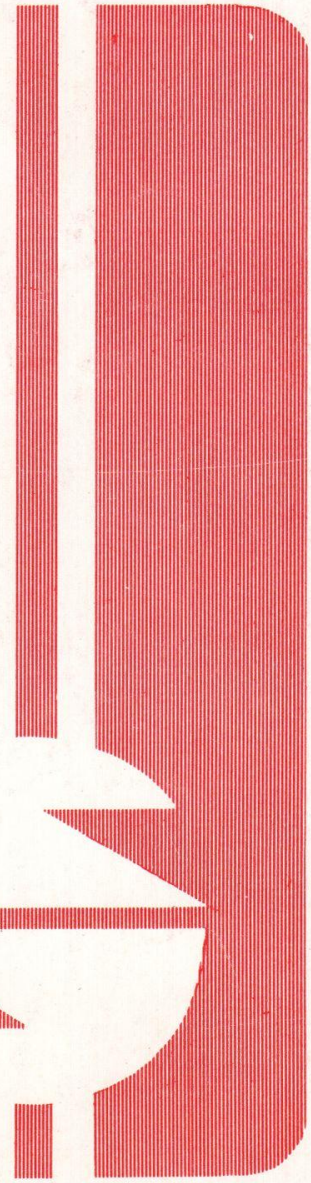


UNIVERSIDADE FEDERAL DO RIO GRANDE DO SUL.

Reitor: Prof. Tuiskon Dick

FACULDADE DE CIËNCIAS ECONÔMICAS

Diretor. Prof. Walter Meucci Nique

CENTRO DE ESTUDOS E PESQUISAS ECONÔMICAS

Diretor. Prof. Reinaldo Ignacio Adams

DEPARTAMENTO DE CIÊNCIAS ECONÔMICAS

Chefe: Prof. Pedro Cezar Dutra Fonseca

CURSO DE PÓS-GRADUAÇĀO EM ECONOMIA

Coordenador. Prof. Roberto Camps Moraes

CURSO DE PÓS-GRADUAÇĀO EM ECONOMIA RURAL

Coordenador. Prot. Aray Miguel Feldens

CONSELHO EDITORIAL:

Achyles Barcelos da Costa, Aray Miguel Feldens, Atos Freitas Grawunder, Carlos Augusto Crusius, Emani Hickmann, João Rogério Sanson, Juvir Luiz Mattuella, Maria Imilda da Costa e Silva; Nali de Jesus de Souza, Nuno Renan Lopes de Figueiredo Pinto, Ot́lia Beatriz Kroeff Carrion, Otto Guilherme Konzen, Paulo Alexandre Spohr, Pedro Cezar Dutra Fonseca, Reinaldo Ignacio Adams, Roberto Camps Moraes, Valter José Stülp, Yeda Rorato Crusius, Edgar Augusto Lanzer (UFSC) e Humberto Vendelino Richeter (UnB)

COMISSĀO EDITORIAL: Atos Freitas Grawunder, Pedro Cezar Dutra Fonseca, Reinaldo Ignacio Adams e Roberto Camps Moraes.

EDITOR: Nali de Jesus de Souza

SECRETARIA: Francisco Carlos Becco dos Santos, Maria Ivone de Mello (normalização), Vanete Ricacheski (revisão de textos), Wagner Nunes e Zélide Bregalda.

FUNDADOR: Prof. Antônio Carlos Santos Rosa

A Revista ANÁLISE ECONÔMICA publica dois números anuais nos meses de março e novembro. O preço da assinatura, para 1990, é de 7,0 BTNs (o número avulso custa 4 BTNs), a ser pago através de cheque nominal em nome da "Faculdade de Ciências Econômicas/ UFRGS". Aceita-se permuta com revistas congêneres. Aceitam-se, também, livros para elaboração de resenhas ou recensōes.

Toda correspondência, material para publicação, assinaturas e permutas devem ser dirigidos ao seguinte destinatário:

PROF. NALI DE JESUS DE SOUZA

Revista Análise Econômica

Av. João Pessoa, 52 - sala 28

90.040 - PORTO ALEGRE (RS) - BRASIL

Telefone: 25-5844 ramal 34 


\section{UMA REAVALIAÇ̃̃O DAS PRIVATIZAÇÕES EM PAÍSES EUROPEUS}

Márcio Wohlers de Almeida*

\section{INTRODUÇĀO}

O objetivo deste trabalho é reavaliar as explicações correntes sobre os propósitos e metas de programas de privatizaçōes desenvolvidos em alguns palses europeus no decorrer da década passada e adicionar hipóteses mais amplas de interpretação, situando a questão no âmbito do processo de reestruturação industrial que vem ocorrendo nos paĺses capitalistas centrais.

A maioria das explicações correntes do fenômeno das privatizações dos anos 80 concentra-se em tópicos estáticos e localizados, tais como a melhoria da eficiência das empresas estatais, a diminuição do déficit público e a eliminação da influência político-governamental na administração dessas empresas. Tais questōes são relevantes, mas por via de regra têm sido utilizadas como racionalização "ex-post" de decisões governamentais e, ademais, não esgotam a problemática da privatização, sobretudo quando entendida como um indicador das mudanças da relação Estado/Economia no capitalismo contemporâneo. A hipótese alternativa deste trabalho é situar tais questões no contexto da reestruturação industrial dos países capitalistas centrais.

O termo privatização vem sendo empregado para designar diferentes propostas no sentido de alterar a relação entre o setor privado e o público, de forma a diminuir a presença do Estado na economia. Genericamente, $o$ termo inclui três proposições básicas:

* Professor do Instituto de Economia da UNICAMP. Atualmente prepara Tese de Doutoramento junto ao IE/UNICAMP sobre o tema das privatizaçర̌es internacionais.

\begin{tabular}{|l|l|l|l|l|}
\hline ANÁLISE ECONÔMICA & ANO 7 & № 12 & NOVEMBRO/89 & p.63-90 \\
\hline
\end{tabular}


1 - desestatização ("denacionalization") das empresas públicas através da venda de ativos de propriedade direta ou indireta do Estado;

2 - desregulamentação ("deregulation") através de medidas para introduzir um maior nivel de concorrência nos mercados não competitivos das empresas públicas;

3 - contratação ("contracting-out") de serviços privados pelo setor público'.

Neste artigo, trataremos apenas dos dois primeiros aspectos do termo ${ }^{2}$. Inicialmente, na parte 2, faremos uma sucinta revisão de alguns programas realizados na Inglaterra, Itália e França e, em seguida, na parte 3, discutiremos as principais razões e argumentações teóricas invocadas para justificar as privatizações inglesas. Na parte 4, vamos propor algumas hipóteses adicionais para a análise, situando a questão no contexto das diferentes estratégias de reestruturação industrial e, finalmente, na parte 5, apresentaremos, a tifulo de debate, algumas considerações sobre temas críticos relacionados com as privatizações.

\section{PANORAMA DAS PRIVATIZAÇÕES INTERNACIONAIS (INGLATERRA, FRANÇA E ITÁLIA)}

A ascensão de governos de corte conservador, tais como os de Reagan, nos Estados Unidos, e Tatcher, na Inglaterra, ao final da década de 70, impulsionou e popularizou de forma extraordinária as propostas de caráter neoliberal, em particular as de privatização. De acordo com esta vertente de pensamento, o enfrentamento dos problemas econômicos, quer de ordem geral, quer de ordem setorial, tanto no capitalismo central como no periférico, necessariamente deveria passar pela implementação de amplos programas de privatização. Dessa forma, no curso da década de oitenta, políticas de privatização e desregulamentação entraram na agenda política de países europeus, dos Estados Unidos, e mesmo de vários palses de industrialização recente.

Nesta seção, faremos uma sucinta descrição e comparação das privatizações ocorridas na Inglaterra, Itália e França, tendo em vista que as empresas públicas destes países respondiam pòr uma proporção sig-

1 THIEMEYER (1986), no contexto do debate europeu, identificou quinze interpretaçoes distintas na utilizaçăo do termo privatização, implicando diferentes formas de retirada do Estado da economia.

2 Para uma discussão do "contracting-out", consultar ASHER (1987). 
nificativa das respectivas atividades econômicas ${ }^{3}$. Ademais, o contraste dessas experiências permite aprofundar o conhecimento e a avaliação do processo. Evidentemente, existem muitas outras experiências internacionais, quer de carăter mais pragmático, a exemplo da venda da automobilistica estatal espanhola SEAT, quer de "deregulation", como do transporte aéreo nos EUA, mas os casos aqui escolhidos permitem ưma primeira abordagem geral ao problema.

As empresas públicas desses três palses se apresentam sob diversas formas-jurídicas e com diferentes graus de autonomia em relação ao Estado, de forma a condicionar fortemente os respectivos processos de privatização 4 .

Näo obstante suas origens serem diversas, tais empresas atuam em atividades consideradas de serviço público, como os setores de energia (eletricidade, gás, carvão e parte do petróleo) e comunicações (transportes ferroviário, aéreo, portos, rádio, TV, correio e telecomunicações). Além de responderem por parte significativa do setor de infra-estrutura e de insumos básicos, à semelhança dos paises latino-americanos, estas empresas têm uma presença estratégica em segmentos específicos da indústria manufatureira e do setor barrcário e financeiro, de forma variada em cada pals.

A inclusāo do tema privatizaçāo na aģenda governamental ocorre de forma extremamente variada entre os paises analisados. O manifesto do Partido Conservador Inglês, pouco antes do seu retorno ao poder, em meados de 1979, dedicava escassa atenção à questão das privatizações. Havia menção explícita apenas a duas indústrias nacionalizadas pelo governo trabalhista (aeroespacial e construção naval) e à empresa de transporte rodoviário - "National Freight Corporation". No entanto, de

3 Os indicadores referentes à participação relativa das empresas públicas no produto bruto, emprego,e formaçáo bruta do capital fixo são, respectivamente, os seguintes - segundo PARIS et alli (1987): Inglaterra (1982), 12\%; 7,4\% e 20\% (valores subestimados pois várias empresas públicas não figuram nas estatisticas inglesas); França(1982, após nacionalizaçర̋es), $17,6 \%, 14,6 \%$ e 34,3\%; Italia(1981), 25,1\%, 26,8\% e 49,7\% (valores superestimados, pois se referem apenas as empresas com mais de 20 empregados, desconsiderando o enorme contingente das pequenas empresas italianas).

4 PARIS et alli (1987) classificaram as empresas públicas em três tipos jurídicos básicos:

a) empresas administradas diretamente pelo Estado ("State Enterprise"), tal como a ferrovia estatal italiana até há pouco tempo;

b) empresas com estatuto especial que permite uma certa autơnomia administrativa e financeira ("State-sponsored Enterprise"), a exemplo das "public corporations" britânicas;

c) empresas regidas pela legislaçăo privada, onde o Estado possui o controle acionário. 
forma lenta, progressiva, e por via de "learning by doing", o programa acabou alcançando dimensōes extraordinárias, principalmente a partir do segundo mandato de Mrs. Tatcher.

Já na França, a plataforma de governo conjunto da RPR e da UDF, apresentada três meses antes das eleições legislativas de março de 1986, explicitava, claramente, que uma das prioridades era o retorno ao setor privado dos bancos, companhias de seguros e indústrias estatizadas pelo governo socialista, em 1982. Esta proposta foi rapidamente encaminhada pelo novo governo de direita após a vitória eleitoral.

Por sua vez, as privatizaçōes italianas nunca configuraram um programa de governo ou foram itens de destaque da agenda governamental nos anos $80^{5}$. As mensagens do governo ao Parlamento, normalmente apenas explicitavam o "campo di intervento" do setor público e deixavam aos organismos da administração pública a escolha das empresas a serem privatizadas.

A formulação e a escolha das alternativas também revelaram profundas diferenças. Na França, as sessenta e cinco empresas a serem privatizadas foram especificadas, de uma só vez, através da lei 86.796 , de $2 / 07 / 86$, e as respectivas modalidades tiveram especificaçōes mais detalhadas através da lei 86.912 , de 6/08/86. Na Inglaterra, foram promulgadas leis especificas para cada uma das privatizações mais significativas, a exemplo do "Telecommunications Act", de 1984, e o "Gas Act", de 1986. Grande parte das empresas públicas inglesas, em particular, as "public corporations", havia sido nacionalizada através de leis específicas e requeria sua transformação em empresas regidas pela legislação privada a fim de ser transacionada no mercado. Na Itália, as decisões relativas à escolha das empresas ou setores a serem vendidos foram deixadas a órgāos e entidades governamentais, tais como as "public holdings" - IRI e INI.

A implementação das privatizações na Inglaterra e na França foi feita pelos próprios governos (Administraçāo Central), após as devidas autorizaçōes do Congresso. Nestes palses, foram montadas estruturas administrativas voltadas especificamente para dirigir e coordenar tais operaçōes, como foi o caso do "Public Enterprise Group", junto ao Ministério do Tesouro britânico, e do "Ministère de l'Economie et de la Privatisation", na França. A situação italiana foi completamente diversa,

5 CASSESE, S. (1988) apresenta um interessante contraste entre as privatizaçбos na Inglaterra, França e Itália. 
pois foram entidades de nível descentralizado que conduziram as operaçōes, tomando as decisões chaves relativas aos preços, condiçōes, modalidades e época de venda.

Vejamos, com mais detalhes, a execução dos programas de privatização, que, necessariamente, são específicos em cada um dos palses.

\subsection{Inglaterra}

A previsão das autoridades britânicas, em 1985, era de que até 1988 a participação das empresas públicas no produto bruto tivesse decaldo para $6.5 \%$, implicando a transferência de cerca de 600 mil empregos para o setor privado. Até abril de 1987, as privatizaçōes inglesas haviam propiciado transações que alcançaram a cifra de 12 bilhões de libras 6 . A tabela exposta a seguir fornece indicações a respeito das privatizações de algumas das grandes empresas dos setores de energia, transporte e da indústria manufatureira.

Muitas outras empresas ${ }^{7}$ de porte variado também foram vendidas através de técnicas e procedimentos bastante diversos ${ }^{8}$. Além da mudança do estatuto jurldico, tal como a transferência das "public corporations" para a legislação privada, foram desenvoividas inúmeras atividades preparatórias ou de "pré-privatização", visando a reestruturação e saneamento financeiro das empresas de forma a torná-las atraentes ao setor privado.

6 Cifra estimada por HEMMING and MANSOOR (1988). A receita das privatizaçðes inglesas é objeto de grandes especulaçбes, principalmente por parte da grande imprensa, que geralmente informa a ocorrência de valores bastante superiores.

7 Além da venda de empresas, deve-se registrar que, entre 1979 e 1983, foram vendidas cerca de 600 mil residências municipais a seus inquilinos, com descontos de até $50 \%$.

8 PIRIE (1985) destaca a utilizaçăo de quatro técnicas de venda, a saber: a) venda integral da empresa, p.ex.: Amersham International, fabricante de radioisótopos; b) venda de parte (mais rentável) da empresa, p.ex.: British Rail Hotels, cadeia hoteleira da ferrovia estatal ou North Sea Oilfields, campos petrolfferos da estatal do carvăo; $c$ ) venda através de sucessivos pacotes acionários, p.ex.: Britoil, British Aerospace, British Telecom, British Gas, e outras; d) venda aos empregados, p.ex.: National Freight Consortium, conglomerado de empresas de transporte rodoviário, à época com cerca de 23 mil funcionários, vendida aos gerentes mais graduados e a motoristas dos caminhóes e funcionários administrativos. $O$ autor também justifica e sugere a distribuiçăo gratuita de açőes das grandes empresas de serviço público à populaçăo em geral. 
TABELA 1

PRIVATIZAÇÃO DAS PRINCIPAIS EMPRESAS PÚBLICAS
INGLESAS ATÉ 1987

\begin{tabular}{lllr}
\hline EMPRESA & \multicolumn{1}{c}{ SETOR } & \multicolumn{1}{c}{ DATA (1) } & VALOR (2) \\
\hline British Aerospace & Ind. manufatureira & fev. 1981 & 43 \\
Cable \& Wireless & Transp./comunicações & out. 1981 & 181 \\
Britoil & Energia & nov. 1983 (3) & 627 \\
Cable \& Wireless & Transp./comunicações & dez. 1983 & 263 \\
Enterprise Oil & Energia & jun. 1984 & 382 \\
Jaguars Cars & Ind. manufatureira & jul. 1984 & 297 \\
British Telecom & Transp./comunicaçōes & nov. 1984 (4) & 4090 \\
British Aerospace & Ind. manufatureira & maio 1985 & 346 \\
Britoil & Energia & ago. 1985 & 436 \\
Cable \& Wireless & Transp./comunicações & dez. 1985 & 571 \\
British Gas & Energia & dez. 1986 (5) & 1796 \\
British Airways & Transp./comunicações & jan. 1987 (6) & 415 \\
\hline
\end{tabular}

Fonte: HEMMING \& MANSOOR (1988)

Obs.: A tabela não inclui as vendas de: a) 19,3\% das ações da British Petroleum, entre 1979 e 1983; b) licenças de exploração no Mar do Norte; e c) participaçōes da National Enterprise Board.

Notas: (1) As datas indicam o início da oferta pública das açōes.

(2) Os dados são em milhões de libras esterlinas.

(3) Sendo 334 milhões de libras em 1982/83 e 293 milhões em $1983 / 84$.

(4) Sendo 1.352 milhões de libras em 1984/85, 1.246 milhões em 1985/86 e 1.084 milhões em 1986/87. Também inclui 408 milhões de libras referentes a outros tipos de ações da BT.

(5) O total estimado ascende a 5.090 milhões de libras. A segunda e a terceira ofertas foram feitas, respectivamente, em junho de 1987 e em abril de 1988.

(6) O valor previsto alcançou 825 milhões de libras e a segunda oferta foi feita em agosto de 1987. 
Para a oferta de ações ao público foram utilizados, de maneira isolada ou combinada, os métodos de oferta com preço pré-fixado ou atravếs de "leilōes" ("tender offer"), sendo o primeiro de maior utilização. Em alguns casos, foram instituldas medidas especiais visando resguardar interesses nacionais, tais como as "golden shares", que permitem impor nacionalidade inglesa a alguns ocupantes de cargos-chave na diretoria, vetar a liquidação da empresa e impedir que acionistas individuais detenham mais de $15 \%$ das ações.

A implementação dessas privatizaçōes desenvolveu-se em duas fases bem distintas. Durante a primeira fase, entre 1979 e 1983, foram desestatizadas principalmente empresas do setor industrial que operavam em mercados não monopólicos e apresentavam bons índices de lucratividade, tais como a British Aerospace, Cable \& Wirelles e Britoil, esta última ligada à exploração e produção de petróleo e gás no Mar do Norte. Também foram vendidas parte das ações que o governo detinha na British Petroleum (operaçāo semelhante havia sido feita pelo governo trabalhista, em 1977), empresa que, em face a seu alto grau de autonomia administrativa e poder de decisão, não podia ser rigorosamente classificada como pertencente ao setor público "nacionalizado". Ainda nesta fase, foram instituldas várias leis, visando diminuir o monopólio detido por algumas empresas, como por exemplo, o "British Telecommunication Act", de meados de 1981, que abriu carninho para maior concorrência na área de equipamentos, operação da rede e suprimento de serviços. Nesse contexto, foi permitido o surgimento de mais uma firma privada no setor de telecomunicaçöes, a Mercury Communications Ltda, para explorar preferencialmente o mercado de comunicaçōes entre empresas, sendo a ela concedido o direito de usar a rede da British Telecom (BT).

Com a reeleição de Mrs. Tatcher ${ }^{9}$, na metade de 1983, inicia-se nova fase do processo, onde será executada a ambiciosa proposta de desestatizar os serviços públicos de telecomunicações e gás, dar continuidades aos projetos em andamento e, também, preparar para o futuro próximo a desestatização dos setores siderúrgico, elétrico e de abastecimento de água. A venda de dez empresas deste último setor ocorreu ao final de 1989.

9 HEALD (1988) observa argutarnente que, em 1983, o Partido Conservador, constatando a iminente derrota argentina na Guerra das Malvinas, vislumbrou uma nova vitória eleitoral $e$ acelerou a elaboraçăo de planos, visando as próximas etapas das privatizaçőes. 
No final de 1984, foram lançados através da Bolsa $51 \%$ das açōes da British Telecom, compradas por cerca de 2,3 milhões de acionistas individuais, além das aquisições feitas por investidores institucionais, inclusive de outros países. Foram instituídos vários esquemas para incentivar a compra, em especial a oferta das açōes por um preço sensivelmente inferior ao de mercado ${ }^{10}$ e também a permanência da posse das açōes por parte dos compradores originais através de desconto nas contas telefônicas, distribuição de um certo número de ações gratuitas para quem não as tivesse revendido, etc. Estes esforços, parece, foram bemsucedidos, pois o número de acionistas não decresceu muito após a venda das ações ao público, decaindo dos 2,3 milhões originais para cerca de 1,7 milhões. A extensão de tais medidas, combinadas com um desconto mais modesto, da ordem de $20 \%$, resultou no surgimento de cerca de 4 milhões de acionistas individuais no caso da British Gas, em 1986. Nesta operação, destinou-se $40 \%$ das ações ao público em geral, $40 \%$ a investidores institucionais, e $20 \%$ a investidores estrangeiros.

Conforme destaca HEALD (1988), a privatização da BT e da British Gas teve quatro características básicas em comum: a) a estrutura básica das empresas foi mantida virtualmente intacta, transformando um monopólio público em privado ${ }^{11}$; b) foram criados organismos de regulamentação para controlar e fiscalizar a operação das empresas ${ }^{12}$; c) foram estabelecidas fórmulas para restringir os aumentos de preços das atividades onde existia o poder de monopólio; d) cada operação de vendas era entusiasticamente comemorada como "a venda do século", onde se proclamava que os maiores beneficiários teriam sido os pequenos acionistas individuais.

\subsection{Itália}

As privatizações italianas foram completamente diferentes, apre-

10 O baixo preço inicial das açס̄es deu origem a um vendaval de operaçбes especulativas, uma vez que os compradores iniciais queriam usufruir o desconto em face ao preço de mercado, aproveitando a oportunidade para realizar "windfall profits".

11 O impacto da nova situaçåo ocorreu já em 1985, quando, para desgosto dos fabricantes bri* tánicos, a BT adquiriu uma empresa canadense produtora de equipamento de comutaçăo automática (Mitel Corporation), em direçăo a uma integraçăo vertical, e foi feito um aumento de tarifas que, nāo obstante obedecer à fómula pré-estabelecida, onerou mais os usuários residenciais do que os industriais.

12 OFTEL (Office of Telecommunication) e OFGAS (Office of Gas Supply). 
sentando-se de maneira bastante peculiar, não apenas pela exclusão do tema enquanto prioridade governamertal, mas também pela própria natureza das empresas públicas italianas, em particular pelo sistema das participações estatais.

Desde a fundação do IRI (Instituto per la Ricostruzione Industriale), em 1933, com o objetivo de impedir que vários bancos italianos entrassem em falência por causa da crise das empresas industriais de sua propriedade, o sistema das participações estatais italianas (IRI, ENI petróleo, EFIM - ind. mecânica) adquiriu extrema fluidez e dinamismo. Participam desse sistema empresas que têm o estatuto jurídico de empresas privadas, onde o Estado tem participação acionária majoritária e, por via de regra, ou são lucrativas ou podem vir a ser. As demais empresas públicas, de natureza mais social e, portanto, não lucrativas (por exemplo, transporte coletivo e correios), não fazem parte desse sistema. O IRI, por exemplo, é um grande grupo industrial, atuando em catorze setores, particularmente siderurgia, telecomunicaçōes, aeroespacial, robótica, fabricação de "cheeps", bens de capital para energia e transportes, e distribuição de alimentos. A receita advinda de suas exportações representa cerca de $40 \%$ do faturamento das atividades manufatureiras. A lógica de atuação do grupo se assemelha à das grandes corporações internacionais. Em periodos de crise, o valor das ações das empresas cotadas em bolsa cai, e há um refluxo do capital privado ("fuga dei privati"), e o reverso acontece em períodos de "boom". Portanto, as privatizaçōes ou estatizaçōes, realizadas a uma escala normal para o respectivo negócio, ocorrem de acordo com as estratégias de mercado.

Durante o período 1980/86, foram vendidas 25 empresas pertencentes ao IRI, envolvendo a transferência de cerca de 51 mil empregos para o setor privado. As privatizações de grandes empresas, como a Alfa Romeo (1987), a Lanerossi (1987), empresa têxtil do ENI, e o banco de investimento Mediobanca (1988), foram feitas diretamente pelas "holding públicas", sem oferta pública de ações ${ }^{13}$. A receita dessas vendas foi apropriada diretamente pelas "holdings" e utilizada para investimentos dos próprios grupos, não obstante os altíssimos níveis da dívida pública italiana. Por exemplo, na venda da Alfa Romeo para a Fiat, considerou-se que a presença do Estado no setor automobilístico não era estratégica, e os recursos advindos da transação foram destinados para

13 As privatizaçס̄es italianas no åmbito do sistema das participaçōes estatais foram bem detaIhadas por ARONICA (1989). 
reforçar as empresas do IRI que atuam na área da robótica, setor considerado estratégico.

Nesse aspecto, a experiência italiana se destaca pelo fato das privatizaçōes virem a fortalecer a presença estatal em setores selecionados, e não o inverso, no sentido de retirada geral do Estado da economia. Em particular, distingue-se ainda a estratégia do IRI na busca de "joint ventures" internacionais nos setores mecânico, aeroespacial, de informática, de fabricação de "cheeps" e outros, onde se inclui a indústria aeronáutica, a exemplo do acordo Aeritália/IRI com a Embraer brasileira, no projeto AMX.

\subsection{França}

O programa de privatizações executado pelo novo governo liberal, encabeçado por J. Chirac, a partir de meados de 1986, não pode ser entendido sem a menção das estatizações feitas em 1982 pelo governo socialista.

O governo de Mitterrand tinha como prioridade a reindustrialização da França de forma a priorizar o mercado interno e, para tanto, era necessário recuperar a capacidade de planejamento do Estado, em particular no tocante às indústrias com fortes poderes de encadeamento interindustrial. Nesse sentido, as estatizaçōes de $1982^{14}$ incluíram cinco grandes grupos industriais estratégicos, dois grupos siderúrgicos, duas empresas de armamentos, três empresas com grande participação estrangeira, três grandes bancos de depósito e duas companhias financeiras.

Como reação a essas estatizaçōes, somada às dificuldades de se implantar a proposta original do Presidente Mitterrand, o novo governo liberal fez aprovar no Parlamento um detalhado programa de privatização de 65 empresas públicas, onde se destacavam a St. Gobain, Paribas, Crédit Commercial de France, Compagnie Générale d’Electricité e Socité Generalé. Entre outubro de 1986 e junho de 1987, foram vendidas 13 empresas públicas, no valor de cerca de FF 55 bilhões. Com exceção da fábrica de vidros St. Gobain, os descontos na fixação dos preços das ações parecem não ter sido tão excessivos quanto na Inglaterra,

14 Para uma descriçăo e análise das nacionalizaçőes francesas de 1982 , consultar DELION et DURUPTY (1982). 
e os compradores iniciais tenderam a conservar as ações. O número de acionistas individuais cresceu bastante na França, quadruplicando o contigente inicial. As receitas das privatizações foram usadas para o pagamento de dívidas e para a capitalização de outras empresas públicas $^{15}$.

Com a volta dos socialistas ao governo, em meados de 1988, o programa de privatizaçōes foi interrompido, e não há indicações de retomada das estatizações.

Finalmente, deve-se ainda mencionar a existência de experiências de privatização em países capitalistas periféricos̀, como em alguns latino-americanos, que têm sido instituldas como componentes de uma estratégia de "ajuste estrutural", com destaque para o problema da dívida externa, geralmente avalizadas por agências internacionais, como o FMI. Algumas dessas experiências aconteceram muito recentemente para serem devidamente avaliadas, como o caso do México, no contexto do plano "Brady". Nias, no caso do Chile, estima-se que as privatizaçōes trouxeram uma grave perda para o patrimônio público, como demonstrou MARCEL (1989).

\section{OBJETIVOS E ARGUMENTOS DAS PRIVATIZAÇÕES INGLESAS}

Considerando que o exemplo inglês é amplamente utilizado para justificar o desenvolvimento de programas de privatizações em outros palses, é necessário aprofundar a discussão e avaliação dos objetivos pretendidos pelas autoridades britânicas.

A análise da literatura disponivel, conforme a referência bibliográfica indicada no final deste trabalho, permite detectar a presença de objetivos de natureza variada, por vezes conflitantes, alguns com maior predominância que outros, dependendo da época e da empresa ou setor a ser privatizado. De maneira geral, a maioria das interpretaçóes correntes identifica cinco tipos de objetivos ou metas a serem alcançadas, a saber: a) melhoria da eficiência econômica das empresas; b) redução da influência político-governamental no processo de tomada de decisão dessas firmas; c) obtenção de receita através da venda de ativos governamentais; d) promoção do capitalismo popular por intermédio da am-

15 DURUPTY (1988) apresenta uma detalhada exposiçăo das privatizaçס̃es francesas. 
pliação da venda de ações para a população; e e) enfraquecimento do poder sindical nas empresas estatais.

Vejamos com mais detalhes o significado e o cumprimento dessas proposiçōes.

\subsection{Melhoria da Eficiência Econômica}

A atenção para a melhoria da eficiência econômica ${ }^{16}$ das empresas públicas é um dos temas de maior destaque na literatura dedicada ao estudo das privatizações inglesas e, usualmente, considera-se a eficiência como critério básico para avaliar o sucesso econômico dos programas.

Desde o início da década de 70, existe uma preocupação crescente com a comparação entre o desempenho econômico das empresas públicas e das privadas, sendo que numerosos estudos emplricos ${ }^{17}$ foram realizados nessa direção, cobrindo diferentes palses e áreas de atividade. No entanto, conforme constata o trabalho de HEMMING and MANSOOR (1988), técnicos do Fundo Monetário Internacional, o resultado dessas avaliações comparativas é rigorosamente inconclusivo, quer devido a problemas metodológicos ligados à escolha e à mensuração dos indicadores de eficiência, quer pela dificuldade de efetiva comparação entre empresas e setores, em face à existência de fatores históricos específicos e de objetivos não comerciais em muitas empresas públicas.

No entanto, tornou-se muito popular a idéia de que as empresas privadas são inerentemente mais eficientes que as públicas, e as autoridades britânicas adotaram tal tese como diretriz básica de seu programa de privatização. John Moore, "Financial Secretary to the Treasury", concluia um discurso em novembro de 1983, afirmando que "os nossos maiores objetivos são o de promover a concorrência e melhorar a eficiência".

16 Em geral săo utilizados dois conceitos de eficiência microeconômica: eficiência produtiva (produçăo ao menor custo unitário) e eficiência alocativa (produção na quanticiade e na qualidade desejada pelo consumidor a preços relacionados ao custo marginal).

17 Veja-se, por exemplo, BORCHERDING et alli (1982) que sumariaram o resultado de vários estudos cobrindo ampla gama de atividades (incluindo tránsportes aéreo, ferroviário e rodoviário, eletricidade, abastecimento de água e seguros) nos EUA, Alemanha Ocidental, Austrâlia, Canadá e Sulça, concluindo pela menor eficiência das empresas públicas, enquanto na revisáo da literatura sobre o mesmo tema, feita por MILLIWARD (1982), a conclusão ê de que nåo há fundamento para tal julgamento. 
O principal instrumento para aumentar a eficiência econômica seria o da concorrência, ou seja, a exposição das empresas públicas à competição. Isto poderia ser alcançado através de uma adequada política de desregulamentação e liberalização nos mercados onde operam tais empresas. As situações de restrição à concorrência na forma de monopólios públicos são identificadas como imperfeiçōes que fatalmente produzem níveis indesejados de ineficiência econômica. Os monopólios "naturais" e os institucionais são encarados como sérias restriçōes à concorrência, e deveria haver políticas especifficas para contornar esses obstáculos, de forma a ampliar o grau de liberalização em alguns monopólios institucionais (por exemplo, transportes aéreo e rodoviário interurbano) e identificar as atividades secundárias, mas competitivas, das empresas operantes em mercados monopólicos a fim de serem liberadas

Entretanto, nota-se que a fundamentação teórica da proposição básica de que a concorrência conduz à eficiência é bastante frágil, pois isto é verdadeiro apenas sob condições bem delimitadas e estáticas. Em uma situação dinâmica, mais condizente com a realidade e adequada à formulação de políticas públicas, os parâmetros são diferentes e mesmo outras noções teóricas de eficiência podem ser introduzidas, como por exemplo a "eficiência shumpeteriana" (introdução e absorção de progresso técnico). Além disso, o desdobramento do binômio concorrência/eficiência poderia conduzir à idéia de que a concorrência leva a menores preços, conforme a suposição neoclássica de concorrência perfeita. Esta é uma conclusão apressada, ou até mesmo falsa, pois normalmente os mercados capitalistas contemporâneos apresentam outras formas de concorrência, em particular a oligopólica, e sua identificação requer no mínimo a especificação da estrutura de mercado e das estratégias de concorrência das empresas atuantes nesses mercados ${ }^{19}$.

A nivel emplrico, o estudo de BISCHOP \& KAY (1988), citado na revista The Economist, de 26/11/88, alerta que o aumento da eficiência econômica (medida através de vários indicadores, incluindo o fator de produtividade total), no período 1983/88, das empresas ainda no setor público foi de ordem semelhante, ou superior em alguns casos, ao das

18 As empresas públicas ịnglesas de gás e eletricidade possufam uma extensa rede de lojas para venda de equipamentos domésticos.

19 Para uma revisáo teórica do conceito de concorrência, estruturas de mercado e oligopólio, consultar POSSAS (1985). 
firmas já privatizadas. Por exemplo, durante o período citado, a produtividade total da British Steel aumentou de $12,4 \%$ ao ano, enquanto o da British Telecom foi de apenas $2,5 \%$ ao ano. $O$ estudo conclui que a propriedade em si não seria o fator decisivo para explicar a eficiência, mas a ameaça da privatização poderia justificar sua elevação, no caso das empresas ainda no setor público.

Como vimos na seção anterior, durante a prìmeira fase das privatizaçōes inglesas, até 1983, foram desestatizadas empresas mais lucrativas e atuantes em setores industriais nāo monopólicos, onde já existia um certo grau de concorrência. Posteriormente, a privatização das grandes empresas operantes nos mercados monopolísticos de telecomunicações e gás foi feita de forma a transformar monopólio público em monopólio privado regulamentado, ou seja, em nenhum dos casos houve uma mudança significativa das condições estruturais de concorrência.

\subsection{Redução da Influência Político-Governamental}

O objetivo da redução da interferência, quer do governo, quer dos políticos em geral no processo de tomada de decisão das empresas, fundamenta-se numa espealfica avaliação da dicotomia propriedade/gerência, observável em qualquer empresa de maior dimensão. Os governos, ou mais especificamente os ministérios tutelares, teriam dificuldades em promover um sistema adequado de acompanhamento e incentivo aos administradores responsáveis pela condução das empresas públicas, os quais deteriam, de forma exclusiva, as informaçōes necessá rias à avaliação do desempenho deles próprios. Dessa maneira, quer pela ausência de recompensas adequadas, quer pela assimetria de informações, os administradores não teriam incentivo para aumentar a eficiência das empresas onde trabalham ${ }^{20}$.

A privatização teria o mérito de permitir aos novos acionistas privados a montagem de um sistema mais efetivo de monitoramento e propiciar meios mais diretos de incentivos e recompensas (por exemplo, por via da participação nos lucros ou outras formas) aos administradores, mesmo na condição de monopólios privados regulamentados. As

20 A "Principal-Agent Theory" é apresentada por VICKERS and YARROW (1988, cap.1) como suporte à proposiçăo de reduçăo da interferéncia governamental nas empresas públicas. 
ameaças de "take-over" no mercado de capitais, ou de falência, impulsionariam os administradores a agirem de forma mais eficiente e produtiva, tornando-os mais responsáveis perante os acionistas privados, os quais buscariam a maximização de seus lucros. Enfim, as empresas privatizadas estariam livres da interferência do governo e dos políticos em geral, que, a priori, é julgada como sendo negativa.

Um maior nível de concorrência complementaria e potensiaria os beneff́cios da privatização, pois a observação do desempenho das firmas concorrentes propiciaria a formação de um sistema de incentivos mais eficiente, e a própria disputa de mercado induziria a uma atuação mais eficiente por parte da empresa privatizada. Além da maior concorrência no mercado de produtos, também é desejada uma maior concorrência no mercado de capitais e de crédito e, sem possibilidade de subsídios ou garantias do governo, as empresas seriam constrangidas a operar de forma mais eficiente e orientadas para a obtenção de lucros, a fim de não descontentar seus acionistas.

Dessa maneira, deveriam ser conjugadas políticas de privatização e desregulamentação de forma a ensejar um alto grau de concorrência no mercado de produtos e de capital ${ }^{21}$. A questão-chave não seria a natureza em si da propriedade - pública ou privada -, mas a interação entre a propriedade e a concorrência, onde o setor privado reagiria de forma mais positiva às pressões da concorrência em direção a níveis mais altos de eficiência. KAY and THOMPSOM (1986) alertam para essa questão, concluindo que "se, existe apenas um pequeno grau de concorrência no mercado de produtos e, ademais, o risco de falência é múnimo, e o risco de aquisição ("take over") é praticamente inexistente, então as forças do mercado irão pressionar os administradores e gerentes responsáveis tanto quanto as formas de controle da administração pública" (p.22).

A reflexão a ser feita sobre esta questāo, é que a interferência governamental, desde uma perspectiva não normativa ou ideológica, não é, em si mesmo, necessariarriente negativa ou perniciosa, mas depende da orientação de política econômica, particularmente da política industrial $^{22}$, dos respectivos governos, e tamberm da estrutura institucional, administrativa e gerencial das empresas públicas, como atestam a flexi-

21 De acordo com KAY and THOMPSOM (1986), a privatizaçăo conduziria à eficiência produtiva e a concorrência à eficiéncia alocativa.

22 O Banco Mundial (Technical Paper № 21) apresentou, em 1984, um minucioso trabalho sobre as polficas industriais implementadas por empresas e palses da OCDE. 
bilidade $e_{0}$ o bom desempenho de grande parte das empresas de participação estatal na Itália.

\subsection{Obtenção de Receita}

Graças a uma particular definição da contabilidade pública inglesa, a estratégia das privatizaçóes adequou-se de forma impecável ao receituário da política econômica de corte monetarista - controle dos agregados monetários e redução do PSBR (Public Sector Borrowing Requirements) - posta em prática pelo Partido Conservador, a partir de 1979. Em pouco tempo de governo, os conservadores constataram que a venda de empresas públicas é muito mais fácil de ser efetuada do que a contenção das despesas públicas ou a elevação da receita.

$\mathrm{Na}$ Inglaterra, a receita proveniente da venda de ativos públicos pode ser contabilmente classificada como "despesa pública negativa"23, contribuindo assim para diminuir diretamente o PSBR. Indiretamente, a privatização também contribui para essa redução, pois as necessidades de financiamento de uma empresa que não mais pertence ao governo deixa de pressionar o PSBR. O montante de receita advinda das privatizaçōes em relação ao PSBR evoluiu de $3,8 \%$, em 1979/80, para $33,7 \%$, em 1984/85 (ROLLAND et VIEILLARD, 1986, p.103).

Entretanto, é necessário verificar as implicaçōes fiscais não apenas em relação ao ano de entrada de "cash", mas em relação ao futuro. Ou seja, o impacto fiscal das privatizaçōes deve ser analisado tanto a curto como a longo prazo, pois a venda de um ativo tecnicamente significa a venda de um fluxo futuro de renda. Se a transação for efetuada por um preço correto, ou seja, pelo valor presente dos fluxos futuros de renda do ativo, não haverá impacto fiscal, e governo e setor privado simplèsmente estarão trocando posiçōes financeiras de ativos e passi$\operatorname{vos}^{24}$. Mas, à medida em que o preço de venda for notoriamente baixo, e os custos de transação forem relativamente altos, haverá uma piora na situação financeira do governo a médio prazo, com o agravante de transferência de riqueza para o exterior, uma vez que se registrou um

\footnotetext{
23 O "Manual on Government Finance Statistics" do FMl recomenda que as receitas provenientes da venda de ativos sejam classificadas como receita de capital ou pagamento de dividas.

24 Para maiores detalhes, consultar HEMMING and MANSOOUR (1988, part. 5).
} 
certo número de investidores estrangeiros, representando uma perda para a economia inglesa.

\subsection{Promoção do Capitalismo Popular}

O crescimento do número de pessoas que possuem ações na Inglaterra foi realmente extraordinário, subindo de $5 \%$ da população adurta, no inficio da década de 80 , para cerca de $20 \%$, ao final do decênio. Embora não haja menção explícita, os portadores individuais dessas ações poderiam vir a ser eleitores do partido que promoveu essas medidas. No entanto, o problema do ponto de vista econômico é que esse aumento do número de acionistas foi obtido através de métodos atlpi$\cos$ do funcionamento do mercado acionário, basicamente por via de generosas subvalorizações do preço de mercado das ações ${ }^{25}$, e à custa de um oneroso processo de promoção e propaganda, além das enormes despesas e taxas cobradas pelos bancos de investimentos e por outros intermediários financeiros para a organização e implementação das operações de lançamento. Ou seja, além da subvalorização do preço de mercado das ações, houve um custo de transação excessivo para os padrōes do mercado acionário variando entre $6 \%$ e $7 \%$ das receitas de venda nos casos da British Telecom e British Gas, e chegando a 11,2\% para a Associated British Ports.

Ademais, existem outras formas de estímulo para a compra de ações, mas a respectiva execução pode vir a requerer o ônus da diminuição relativa de incentivo a outras formas de poupança.

\subsection{Enfraquecimento do Poder Sindical}

Quanto ao objetivo político de enfraquecer o poder sindical nas empresas públicas, a argumentação inicia pela constatação do alto grau

25 VICKERS and YARROW (1988, cap. 7) mostram de forma detalhada o processo de subvalorizaçăo das privatizaçర̄es inglesas, como no caso British Telecom, onde o preço de oferta de cada açăo foi fixado pelo governo em 130 pence (a ser pago em três prestaçōes) e, no final do primeiro dia, cada tfulo valia 173 pence ( $33 \%$ a mais), chegando a ser transacionado até por $90 \%$ a mais do valor inicial, quando a média de subvalorizaçăo da Bolsa de Londres no lançamento de açठ̄es privadas é de cerca de 5,3\%. Estes autores estimam que a subvalorizaçăo das privatizaçōes inglesas, representadas em temos de valores globais, atingiu cerca de 3 bilhoes. 
de organização e capacidade de obter benefícios por parte dos sindicatos dessas empresas. No entanto, tal apreciação deve ser amenizada, pois, em última instância, a obtenção de benefícios depende da orientação política do governo, que pode agir em sentido contrário, por exemplo, "aguentando" uma greve à custa de perdas financiadas pelo próprio governo. BOOTLE (1987) constata que houve uma melhoria nas relaçōes de trabalho na Inglaterra, mas que essas tiveram muito pouco a ver com as privatizaçöes, que apenas "has played some part in changing attitudes and increasing attention to profitability" (p.10).

Estas avaliaçōes permitem concluir que, no caso inglês, houve uma certa preponderância dos objetivos relacionados com a geração de receita e a promoção do "people's capitalism" em relação às demais metas que se tornaram secundárias ou foram atingidas muito parcialmente. Registrourse, também, um claro conflito de objetivos, particularmente entre a diminuição do PSBR e a promoção do "people's capitalism", uma vez que a promoção deste último fez-se as custas de significativas perdas de receita.

A apreciação das privatizações internacionais dos anos 80 feita pela revista The Economist, de 23/12/89, é bastante significativa: "Beneflcios alegados: ampla extensão da participação acionária, bilhōes de dólares para os cotres públicos e poucos sinais de uma melhor administração. Prejứzos: poucas das novas empresas privatizadas defrontaramse com alguma concorrência" (p.92).

No entanto, a avaliação das privatizações apenas sob o ângulo destas proposiçōes é insuficiente para se perceber a existência de outros níveis de determinação. Existem outros fatores explicativos, ordem estrutural e dinâmica, relacionados com o comportamento das economias capitalistas centrais no decorrer das décadas de 70 e 80 , conforme veremos a seguir.

\section{AS PRIVATIZAÇÕES NO CONTEXTO DA REESTRUTURAÇÃO INDUSTRIAL}

Uma parte significativa das empresas públicas dos palses analisados está localizada em setores direta ou indiretamente afetados pelo atual processo de reestruturação industrial dos capitalistas avançados.

Dessa forma, a problemática das privatizações nos palses capitalistas avançados extrapola o âmbito das intenções polfticas e objetivos 
de natureza fiscal dos governos (como no caso inglês) e se insere na lógica da atual reestruturação industrial. Ou seja, o estudo das privatizaçōes também é o estudo das mudanças do papel do Estado, e das empresas públicas em particular, na articulação e sustentação de um determinado padrão de crescimento econômico e das respectivas trajetórias tecnológicas que vigoraram desde o pós-guerra até o início da década de $70^{26}$.

Nesta fase do crescimento das economias capitalistas, não apenas em seu" conjunto, mas de acordo com as especificidades históricas de cada pals, houve um determinado padrão de intervenção do Estado, desempenhando funções de regulaçāo macro e microeconômicas e de maior ou menor grau de intervenção produtiva ${ }^{27}$.

A rápida expansão econômica dos palses capitalistas centrais desde o pós-guerra até o final dos anos sessenta esteve centrada em uma grande expansão do setor industrial (liderado pelo complexo metalmecânico e químico), que impulsionava e transformava outros setores econômicos, notadamente agricultura, serviços e comunicaçōes. A base técnica desse crescimento fundava-se na eletromecânica e, desde os anos vinte e trinta, já havia se difundido entre os países industriais. Havia, nesta fase, uma alta interação entre progresso técnico, crescimento e comércio internacional de manufaturas e, ao mesmo tempo, incorporavam-se as vantagens de uma fonte de energia barata - o petróleo ${ }^{28}$.

O dinamismo desse crescimento era corporificado no grande capital oligopolista norte-americano, que através da rápida expansão de seu subsistema filiado e da contra-resposta dos grandes oligopólios europeus, terminou por desdobrar sua estrutura tecno-industrial e seus padröes de consumo em escala internacional.

Este padrão de crescimento exigia uma presença ativa do Estado a fim de estruturar amplos aspectos da vida econômica e social, em particular para:

26 Nos anos do pós-guerra, época de montagem e consolidaçăo do "welfare state", houve um interessante debate sobre forças de mercado versus planejamento, e setor público versus setor privado. Anteriormente, nos anos de entreguerra, também houve a discussăo sobre as possibilidades do cálculo racional no socialismo, contando com a participaçăo de economistas de renome internacional, tais como Oskar Lange, Ludwig von Mises e Abba P. Lemer. Para uma revisão dos debates, consultar LANGE (1971).

27 Para uma definiçăo das formas de intervençăo do Estado nas economias capitalistas, consultar ALTVATER (1972).

28 Uma excelente descriçăo do padrăo de crescimento tecnológico dos palses capitalistas centrais encontra-se em FAJNZYLBER (1983). 
- regular as condições de trabalho e promover o "welfare state";

- socializar importantes custos econômicos, absorvendo (estatizando) ou regulamentando atividades significativas do setor privado, notadamente na área de infra-estrutura e insumos básicos ${ }^{29}$;

- regulamentar amplamente o funcionamento do sistema firanceiro e mesmo da própria concorência intercapitalista ${ }^{30}$.

No entanto, a crise que emergiu nos anos setenta revelou contradições de ampla envergadura neste padrão de crescimento. A perda de dinamismo do crescimento industrial que aparece no final da década de 60 , os problemas de regulação inerentes à profunda transnacionalização produtiva e financeira, somados à profunda crise internacional dos anos 70 , demonstraram a impossibilidade da continuidade daquele padrão e contribuiram para corroer as bases econômica e polftica do intervencionismo keynesiano clássico.

Os anos 70 mostraram uma ruptura das trajetórias do crescimento industrial a nivel mundial. Desde o pós-guerra até 1971, o crescimento da indústria mundial ocorre a uma taxa entre 6 e $7 \%$ ao ano ${ }^{31}$. A partir dessa data, o crescimento decai para uma média de cerca de $2,5 \%$ ao ano, acusando ainda grandes variações conjunturais. Os ramos industriais motores do padrão de crescimento anterior, notadamente quimico, automobilístico, mecânico e de equipamentos elétricos são aqueles que sofrem uma queda mais marcante. A siderurgia e a metalurgia de base passam por uma situação verdadeiramente calamitosa. $A$ indústria têxtil e a agroalimentar, cujo crescimento já não era significativo, são relativamenté pouco afetadas. Em compensação, algumas indústrias consideradas de ponta, tais como informática, eletrônica de consumo e profissional, aeronáutica e química fina passam por uma fase de crescimento excepcional.

São justamente algumas empresas de porte, situadas em indústrias maduras, que entraram em crise nos anos setenta, tais como siderurgia, construção naval e automobilística, que receberam ajudas subs-

29 A teoria económica neoclássica tradicional alega a existência de "falhas de mercado", tal como o monopólio "natural" - mercado onde os custos de produçăo săo monotonicamente decrescentes -, para justificar este tipo de intervençăo do Estado.

30 O papel do Estado na articulaçăo do sistema financeiro e da concorrência intercapitalista no pós-guerra é descrito por alguns autores através da categoria Capitalismo Monopolista de Esiado. Para uma revisåo crftica do conceito, ver TEIXEIRA (1983).

31 Dados referentes ao desempenho industrial mundial citados neste parăgrafo sáo de STOFFAES (1989). 
tantivas dos governos dos respectivos paises, no limite chegando à forma de estatizaçōes. Apenas para citar alguns dos muitos exemplos, na Inglaterra, já em 1971, a Rolls Royce foi estatizada em função de dificuldades financeiras ligadas à execução de um grande projeto de motores (que depois terminou bem-sucedido). Mas, depois da crise de 1973, muitas empresas públicas ou mesmo privadas dos setores em crise receberam grandes empréstimos e subvençōes governamentais, destacando-se a British Steel, British Shipbuilding, British Leyland e Chrys ler-UK. Tais ajudas foram provenientes de governos tanto conservadores como trabalhistas. Na Suécia, na esteira da crise de 1973, foram estatizados grandes estaleiros de construção naval e usinas siderúrgicas. $\mathrm{Na}$ França, a partir de 1975 , foi posto em prática um plano sistemático de sustentação de empresas em dificuldades através do CIASI. Mesmo nos Estados Unidos, onde tradicionalmente sảo defendidas as regras de mercado, a Chrysler, a partir de 1976, recebeu garantias do governo federal para empréstimos contraldos junto ao setor bancário.

Portanto, ao assumir tais operações de "salvamento" no contexto da crise dos anos 70, os governos de vários palses europeus agiram em função da sustentação do emprego e da renda, do não agravamento de desequilíbrios regionais, da garantia de suprimento, ou ainda por pressões coorporativas, ou seja, por valores extramercado. Assim, nāo há surpresa na constatação de que os indicadores de eficiência dessas empresas tenham sido altamente desfavoráveis.

Ao final dos anos 70 , há uma gradativa tomada de consciência de que a perda de dinamismo da economia mundial tem origens estruturais, não se reduzindo às dificuldades conjunturais, tais como as oscilações do preço do petróleo ou das taxas de câmbio ${ }^{32}$. As rupturas desse padrão de crescimento pelo lado monetário, a partir de 1969 e pelo lado do fornecimento de insumos, particularmente por via dos choques de preço do petróleo nos anos 70 , são bastante conhecidas. No entanto, conforme apontou STOFFAES (1989), a ruptura pelo lado industrial é menos visivel, e ocorre de forma não datada e gradualmente, ou seja, suas causas e efeitos são apreendidos "ex-post".

Em suma, a crise do padrão de crescimento industrial ocorre pela saturação do padrão de consurno e pelo esgotamento dos ganhos de produtividade (proporcionados pela expansão dos setores que lideraram

32 A crise dos anos 70 é analisada de forma impecável por FAJNYZILBER (1988). 
a expansão), agravada ainda pela "implosão" do arcabouço financeiro e institucional que havia presidido aquela expansão ${ }^{33}$.

Os Estados nacionais perderam grande parte de sua autonomia frente à profunda internacionalização dos sistemas produtivos e dos mercados, e também pela tendência de unificação monetária e financeira que acompanha este processo. Além do enfraquecimento do poder de regulação de coordenação do Estado, verificam-se pressōes para o aumento do gasto público em funçăo da ampliação de demandas sociais e econômicas, em um momento de restrição de sua capacidade de financiamento em face à redução do nivel de atividades.

Não obstante tais restrições, empresas e governos dos paises capitalistas industrializados estão implementando diferentes estratégias de reestruturação industrial. De forma diferenciada, estão sendo coordenadas políticas macroeconômicas e políticas setoriais de reestruturação, com énfase variada no mercado externo e interno, no sentido de recuperar ou manter o dinamismo industrial, em um ambiente de altíssima concorrência internacional e de mudanças na direção dos fluxos internacionais de capitais ${ }^{34}$. A perspectiva de formação de macromercados como a unificação Européia de 1992, está acelerando ainda mais o dinamismo da concorrência internacional.

A transigăa a um novo padrão de crescimento e a recomposição da base tecnológica começa a se esboçar com o crescente desenvolvimento e difusāo de novas tecnologias a nivel de produto e processos, baseados principalmente em avanços nas áreas da microeletrônica, informática, novos materiais e novas formas de produção e transmissão de energia, representativos da introdução de um novo paradigma tecnológico. Esses avanços tecnológicos têm como característica não se circunscrever ao setor industrial, mas rapidamente espraiar-se para outros setores econômicos e para a sociedade como um todo.

Desenvolvem-se igualmente novas técnicas de gestão, de organização industrial, de estratégias de mercado, reformulando-se o próprio padrão concorrencial. Registram-se grandes mudanças a nivel da reorganização produtiva, onde estão sendo alteradas a extensão absoluta dos mercados, as economias de escala técnicas e econômicas, as estra-

33 Sobre o tema, consultar MIRANDA (1988).

34 Para uma apreciaçáo das diferentes estratégias de ajustamento estrutural, ver MIRANDA (1987). 
tégias de localização regional e internacional, e as formas de integração entre empresas.

A emergência de novos padrões tecnológicos, organizacionais e concorrênciais, exigindo estratégias de reestruturação a longo prazo, somados aos problemas de regulação inerentes à profunda transnacionalização produtiva e financeira, induz a mudanças nos padrōes de intervenção do Estado e ao estabelecimento de um novo tipo de articulação entre o setor público e o privado.

Em termos concretos, se distingue uma estratégia neoliberal, que ressalta a importância da internacionalização e do mercado externo como fonte de dinamismo, onde se enquadram os Estados Unidos e a Inglaterra, e uma estratégia socialmente negociada, de inspiração keynesiana, onde, não obstante destacar a importância da competitividade, há mais ênfase no mercado interno e na atuação do Estado para alocar ganhos de produtividades e renda, e desenvolver ações de cunho estruturante. Neste segundo caso, se encaixam a Itália e a França, sendo que o Japão e a Alemanha Ocidental desenvolvem estratégias híbridàs.

De maneira geral, as privatizações dos países capitalistas industrializados são parte de ambas estratégias e a elas se subordinam. Embora registrem-se privatizações nos dois casos, sua intensidade e motivaçạo são bastante diferentes, de acordo com as orientaçōes estraté gicas e as particularidades setoriais.

Apenas a título de exemplo, pois a reestruturação industrial é um fenômeno extremamente complexo, com especificidades para cada setor e ramo industrial, vamos observar as transformaçōes em curso em três setores industriais chaves:

a) indústria automobil'stica: as mudanças são profundas, atingindo os niveis da reorganização da indústria, da estrutura de mercado e, fundamentalmente, da base técnica, "através da introdução das técnicas de CAD/CAM, sistemas de automação flexivel de fabricação, robótica", conforme a descrição de SUZIGAN (1988, p.9). Dessa forma, os esforços a serem feitos, pelas então estatais Alfa Romeo italiana, SEAT espanhola, e British Leyland inglesa seriam altíssimos, e a solução mais racional e realista foi deixar para o setor privado a implantação dessas alteraçōes.

b) indústria siderúrgica: a crise da indústria siderúrgica é um fenômeno de dimensão internacional, quer pela mudança do perfil da demanda, como por exemplo a maior utilizaçäo de aços especiais pelas indústrias automobillstica, mecânica e aeroespacial, quer pelo excesso 
de oferta, advindo de sobreinvestimentos, quer pela redução relativa do volume da demanda, em função da substituição por outros materiais (por exemplo, plásticos). Nesse sentido, o esforço da siderurgia européia, em sua maioria estatal, é de racionalizar e reduzir a capacidade produtiva, adequando-a a novos perfis de demanda. Em face à dimensão da crise, é muito difícil que o setor privado tenha interesse por sua aquisição, a menos que seja possível efetuar rapidamente um saneamento financeiro e produtivo, implicando fechamento de plantas, demissão de grandes contingentes de mão-de-obra, com implicações de agravamento de desequilíbrios regionais, etc. A British Steel está ultimando um processo de mudanças nesse sentido e sua privatização foi anunciada no final de 1988.

c) equipamento para telecomunicaçōes: está havendo uma notável mudança na tecnologia de comutação em direção a sistemas eletrônicos sofisticados, novas tecnologias de transmissão e aplicação da eletrônica nos equipamentos terminais e, conseqüentemente, com grandes implicações na área de telecomunicações. Há possibilidade de surgimento de novos serviços "de alto valor agregado" que não são monopólios "naturais" e podem ser operados pelo setor privado, de forma mais competitiva, utilizando-se a rede nacional de telecomunicaçōes.

Acreditamos que, a partir do enquadramento acima esboçado, é possivel reavaliar o sentido das privatizações internacionais. Dessa maneira, as questões de eficiência microeconômica não mais se constituem em tópicos isolados e estáticos, mas se articulam com as determinações mais gerais advindas das diferentes estratégias de reestruturação industrial.

O surgimento de um novo paradigma tecnológico estabelece um amplo espectro de possibilidades produtivas e distributivas, que serão desenvolvidas a partir da conformação de um marco sócio-institucional coerente, geralmente implantado através de um gradual processo de acertos e erros.

\section{CONCLUSÕES}

Cada país tem uma específica história de desenvolvimento industrial que condiciona as formas de futura inserção no cenário internacional, ou seja, a reestruturaçāo industrial nāo é um processo aberto, assim como não são as privatizações. Dessa maneira, as estratégias perse- 
guidas durante a década de 80 pelos governos inglês e italiano constituem casos extremos, e representam propostas nitidamente excludentes de redefinição do papel de Estado, tanto em resposta as novas condiçōes da economia internacional após a crise dos anos 70 e início dos 80 , como em relação à reestruturação industrial.

Menos a título de conclusão, e mais como contribuição ao debate, ressaltaremos algumas questões de ordem mais geral, a fim de encaminhar a discussão:

- a) a questão estatização versus privatização não é uma problemática nova no capitalismo contemporâneo nem pode ser reduzida a uma genérica busca de eficiência. Recentemente, vários autores vêm chamando a atenção para o caráter cĺclico da intervenção estatal no capitalismo contemporâneo ${ }^{35}$;

b) nas privatizações inglesas, onde prevaleceram interesses fiscais de curto prazo e a promoção do "people's capitalism", deve ser reconsiderada a questão do declínio histórico da economia britânica, em que a intervenção do Estado e o surgimento de um grande conjunto de empresas públicas no pós-guerra não foi capaz de contrabalançar tal tendência, que se arrasta desde o final do século passado;

c) o papel de coordenação do Estado, independentemente do grau de sua intervenção produtiva, é insubstitulvel enquanto agente de estruturação de setores industriais tecnologicamente avançados, como ilustram os casos do Japão (através do MITI) e da Coréia do Sul, que desenvolveram de forma eficiente, e concertada com os interesses privados, dinârnicos esquemas de planejamento e de alocação de recursos públicos em pesquisa e desenvolvimento;

d) é necessário aprofundar o conhecimento teórico e empírico das estratégias de concorrência dos setores privatizados, afim de melhor avaliar os resultados em relação às eficiências produtiva e alocativa;

e) a privatização de serviços públicos tradicionais operados por monopólios públicos, em países com maior incidência de desequilíbrios na distribuição de renda, e que também apresentam grandes desniveis regionais, levanta a questão da capacidade do Estado tanto na implantação de agências regulatórias que não sejam "capturadas" pelos novos produtores privados, como induzir o atendimento a todas as faixas de mercado e não apenas as mais rentáveis;

f) no contexto dos países capitalistas periféricos, em especial os

35 Como, por exemplo, GERMIDES (1988) e PEREIRA (1989). 
latino-americanos que, nesta década, além de sofrerem uma profunda deterioração de suas economias, foram submetidos a um violento processo de endividamento externo e interno, apresentando também inusitados índices inflacionários, a questão da privatização em larga escala deve ser analisada no tocante a dois aspectos centrais:

i) em que medida sua implantação generalizada poderá possibilitar uma inserção positiva no cenário internacional, viabilizando a introdução de setores tecnologicamente avançados e com impactos significativos na estrutura industrial?

ii) em que medida pode a privatização fazer parte de uma estratégia decisiva de reversão do atual quadro de distribuição de renda, permitindo o resgate da "dívida social"?

\section{BIBLIOGRAFIA}

ALTVATER, E. Notes on Some Problems of State Intervention. Kapitalistate, n. 1, Berlim, 1972.

ARONICA, A. Le Privatizzazioni Nelle Participazioni Statali: uno Studio di Casi. In: MAJO, Antonio di. Le Politiche di Privatizzazione in Italia. Bologna, Il Mulino, 1989.

ASCHER, R. The Politics of Privatization. Contracting Out Public Services. London, Macmillan Education, 1987.

BISHOP, M. \& KAY, J. Does Privatization Work? Lessons from the UK. London, London Business Scholl, Sussex Place.

BOOTLE, R. Privatization, Speech. (São Paulo, 7.10..1987). World Financial Developments. London, Lloyds Bank, 1987.

BORCHERDING, T., POMMEREHNE, W. \& SCHEIDER, F. Comparing the Efficiency of Private and Public Production: the Evidence from Five Countries. Zeitschrift für Nationalokonomie (Suplemento 2), p.127-56, 1982.

CASSESE, S. Privatizzare allitaliana. Politica et Economia, n. 4, 1988.

DELION, A. \& DURUPTY, M. Les Nationalisations. Paris, Economica, 1982.

DURUPTY, M. Les Privatisations en France. La Documentation Française, ND n. 4857, Paris, 1988. 
FAJNZYLBER, F. La Industrializacion Trunca de America Latina. México, Editorial Nueva Imagem, 1983.

. Competividad Internacional: Evolución y Lecciones, Revista de la CEPAL, n. 36, dez. 1988.

GERMIDES, G. Towards a Better Balance Between Public and Private Sector in Developing Countries. I Conferência Internacional Sobre Estatização, Privatização e Eficiência Econômica. São Paulo, PLANEF/OCDE, 1989.

HEALD, D. United Kingdon: Privatization and its Political Context. Symposium in Western Europeans Politics. (forthcoming), 1988.

HEMMING, R. \& MANSOOR, A. Privatization and Public Enterprises. Washington, International Monetary Fund, 1988 (Occasional Papers, n.56).

KAY, J.A. \& THOMPSON, D.J. Privatization: a Policy in Search of a Rationale. Economic Journal, 96(1986): 18-32.

LANGE, O. On Economic Theory of Socialism. In: TOWNSEND, H. Price Theory, London, Penguin, 1971.

MARCEL, M. Privatización y Finanzas Públicas: el Caso de Chile, 198588. Colección Estudios CIEPLAN, N. 26, junio, 1989 (Santiago de Chile).

MILLWARD, R. The Comparative Performance of Public and Private Ownerschip. In: ROLL, Eric. The Mixed Economies. London, Macmillan, 1982.

MIRANDA, J.C. Estratégias de Ajustamento Estrutural dos Paises Capitalistas Avançados. Campinas, UNICAMP/IE, mimeo, 1987 (Texto Para Discussão n. 8).

. Tendências Atuaís da Reestruturação do Sistema Produtivo Internacional. Campinas, UNICAMP/IE, mimeo, 1988.

PARRIS, H., PESTIEAU, P. \& SAYNOR, P. Public Enterprise in Western Europe. London, Acton Society Trust, 1987.

PEREIRA, L.C.B. O Caráter Cíclico da Intervenção Estatal. Revista de Economia Política, vol. 9, n.3, jul./set. 1989.

PIRIE, M. Teoria y Practica de la Privatización de la Empresa Publica. Revista del Instituto de Estudios Economicos, n.1, Madrid, 1985. 
POSSAS, M.L. Estruturas de Mercado em Oligopólio. São Paulo, Hucitec, 1985.

ROLLAND, Y. \& VIEILLARD, P. Les Privatisations en Grande-Bretagne. Denationalisations - Les Leçons de l'Étranger. Paris, Economica, 1986.

STOFFAES, C. Restructuration Industrielle Recente dans les Pays de IOCDE. I Conferência Internacional Sobre Politica Industrial e Desenvolvimento Econômico. São Paulo, PLANEF/OCDE, 1989.

SUZIGAN, W. Reestruturação Industrial e Competitividade nos Países Avançados e nos NICs Asiáticos: Lições Para o Brasil. Campinas, UNICAMP/IE, 1988.

TEIXEIRA, A. Capitalismo Monopolista de Estado: um Ponto de Vista Crítico. Revista de Economia Política, vol. 3, n.4, out./dez., 1983 (São Paulo).

THIEMEYER, T. La Privatisation des Enterprises Publiques: un Débat Européen. Annales de l'Économie Publique, Sociale et Cooperative, n.2, juin, 1986 (Paris).

VICKERS, J. \& YARROW, G. Privatization: an Economic Analysis. G.B., MITT Press, 1988. 